\title{
Foreword
}

\section{Animal fibre: connecting science and production}

\author{
H. Galbraith ${ }^{\dagger}$ \\ Institute of Biological and Environmental Sciences, University of Aberdeen, 23 St Machar Drive, Aberdeen, AB24 $3 R Y$ UK and Department of Environmental and \\ Natural Sciences, University of Camerino, Via Pontoni 5, 62032, Camerino, Italy
}

(Received 11 January 2010; Accepted 18 March 2010; First published online 10 May 2010)

Keywords: animal fibre, economic value, hair follicle biology, fibre properties, genetic improvement

\begin{abstract}
Animal fibre as a natural resource and economic value
Hair fibres from a range of domesticated and undomesticated animal species have long provided valuable products for use by the human population. Historically, sheep hair fibre described as 'wool', has been an important source of economic wealth for European countries with production surpassed in recent times by Australia and New Zealand. Sheep wool is also an important product of China and South American countries. Other natural animal fibre products and major regions of production include alpaca, llama, vicuña and guanaco (South American camelids: South America), mohair (Angora goats: Southern Africa; Turkey; United States; and Argentina), cashmere (Goats: China; Mongolia; and Iran) and angora (Rabbits: range of countries). The scale of world 'wool' production has been estimated at 2.2 million metric tonnes (mt) (van Dam, 2009) with Australian sheep wool contributing in excess of 0.4 million mt (Lyons, 2009). Production of other fibres includes that from alpaca (4056 mt) and llama (3343 mt) in South America (Cardellino and Mueller, 2009) and raw cashmere in China (8900 mt) (Jianchun, 2009). In terms of utilisation of the raw or partly processed sheep wool product, China is the major international centre of importation $(276700 \mathrm{mt}$ ) and processing (359 $700 \mathrm{mt}$ ) (Jianchun, 2009). In regard to examples for Europe, approximate values for importation of wool into Italy and the United Kingdom for the year 2000 are given as $150000 \mathrm{mt}$, and $90000 \mathrm{mt}$, respectively (Lyons, 2009). There is, in addition, industrial and 'niche market' use of indigenous animal fibre produced in European countries such as France (Allain and Renieri, 2010), Italy (e.g. Biella the Wool Company, 2009) and United Kingdom (British Wool Marketing Board, 2009). The importance of natural fibres
\end{abstract}

† E-mail: h.galbraith@abdn.ac.uk from animals for both producing and processing interests was recently highlighted in the activities associated with 2009 as the 'International Year of Natural Fibres' (Common Fund for Commodities, 2009a and 2009b).

In relating biology to economic value, it is important to be aware that fibre is produced by specialised follicles located in skin of animals and is composed principally of keratinbased protein. The end-use of the finished product is determined by physical properties of the fibre that include length and diameter. Lyons (2009) has summarised many of the qualities of natural fibres, which following processing by a range of techniques, make them attractive to consumers including those in urban environments where the preference is frequently for light and comfortable woven and knitted garments. Small-diametered fibres such as cashmere, alpaca and finer merino are used mainly in such high-value woven garments. Fibres with progressively greater diameters are used for less fine garments, household textiles, floor coverings and house insulation. Examples of monetary value, in 2007, for export of fine and good quality wools for South American countries are given as \$US 600 million (Cardellino and Mueller, 2009) and for Australia (2003 to 2004), \$AU 2.3 billion (Lyons, 2009). Examples of sociological value suggest that animal fibre contributes to the wealth of 600000 farmers in South America (Cardellino and Mueller, 2009) with 30000 farms involved in Australian sheep wool production (Lyons, 2009).

\section{Scientific knowledge and its development, and} application in global animal fibre production

There has been a reduction in demand for animal fibre production in the past 5 to 20 years that has also seen decreases in the international science base. This is exemplified, for example, in Australia where the Commonwealth Scientific 
and Industrial Research Organisation (CSIRO) wool research laboratories have been reduced in number to one (Rogers, 2006), and United Kingdom with reduced fibre research programmes at the Macaulay Institute, Aberdeen and decreases in Agriculture Faculties in Universities such as Aberdeen.

Against this background the Department of Environmental and Natural Sciences at the University of Camerino, Marche Region, Italy has maintained a particularly important presence in scientific investigation. It has done this by consolidating former, and developing new, partnerships with research scientists and Centres in Europe, China, South America and Southern Africa. One recent outcome of such development was the presentation to EU Framework 6 of a proposal to investigate arid and semi-arid ecosystems management and sustainability of animal-fibre production systems. This proposal recognised the global environmental dimension of livestock production for fibre. It sought to research and test methodologies designed (i) to improve the economic value of the fibre product of each animal by increasing focus on quality of end product and (ii) reduce adverse environmental impact by reducing inefficient use of land by poorly performing animals. The project was designed, in addition, as a European contribution to meeting Millenium Development goals by particular targeting of rural agriculture in South American countries. Although the application was not funded, the pressing need for enhanced biological and ecological knowledge to improve fibre production remains. It should also be noted that the importance of animal fibre production continues to have limited recognition by funding bodies and the subject apparently does not feature in EU Framework 7 (http://cordis.europa.eu/fp7/). This deficiency should be addressed.

\section{European Association for Animal production and Animal Fibre Working Group Workshop, Vilnius 2008}

The above scientific relationships contributed to the formation of the Animal Fibre Working Group (AFWG) in 2007, under the auspices of the European Association for Animal production (EAAP). Office-bearers are Professor Carlo Renieri (University of Camerino, Italy) as President, with vice-Presidents $\mathrm{Dr}$ Daniel Allain (INRA, Toulouse, France), Dr Hugh Galbraith (University of Aberdeen, UK) and Professor Martina Gerken (Georg-AugustUniversität Göttingen, Germany) as Secretary. The working group organised a workshop to consider 'The European research on fine fibre-producing animals' at the 59th EAAP Annual Meeting in Vilnius, Lithuania. Contributors included delegates from the fibre processing industry, primary producers and research scientists. The presentations of the scientists form the basis of the collection of papers in this proceedings of the Workshop and contain relevant bibliographies. A brief foreword is provided for each as follows.

The paper of Gerken (2010) takes a 'whole' animal approach in identifying the origins and properties including medullation of hair coats from primary and/or secondary hair follicles (HFs) in South American camelid species. The anatomical location of HFs in skin and hair fibre in contributing to thermoregulation both in terms of heat retention in cold climatic conditions and heat loss as a mechanism to avert heat stress is described. Thermal conductance in winter was shown to be less than that exhibited by pelage in summer. The results from studies designed to quantify the effects of shearing demonstrated potentially beneficial effects to reduce heat stress and, in male animals, under hot conditions to improve fertility. The author advises caution, however, where shearing under cold conditions may give rise to hypothermia according to increased heat conductivity depending on length of residual hair. Such conditions are recognised as having important implications for animal welfare.

The paper by Antonini (2010) addresses the question of hair fibre phenotypes according to a range of genotypes of both Llama and Alpaca as commercially important South American camelids. Attention is given to differences in physical characteristics of fibre of Huacaya (crimped, blunttipped fibres) and Suri ('corkscrew,' lustrous fibres) alpaca genotypes. These genotypes contribute approximately 0.9 and 0.1 respectively of alpaca fleeces harvested in Peru. Similarly, two genotypes of Llama are studied namely "Q'aras" (double-coated) and 'Chaku' (or T'ampullis) (essentially single, secondary follicle-coated with primary follicle contaminants). Attention is given to anatomy and dynamic behaviour, including secondary to primary ratio and effects of postnatal development and season/photoperiod on HF cycle, of the different types of follicles in skin. Techniques used included electron microscopy and histological evaluation of skin, fibre and follicles. Information is provided on distinguishing properties of fibres such as HF density, cell cuticular structure (scale height and frequency), diameter and medullation. The genetic basis for the observed variations in $\mathrm{HF}$ and fibre parameters are discussed and recommendations made concerning the selection of animals for breeding and timing of shearing to optimise production of finest quality of fleeces which, for Llama, are produced by kids. Such decisions will also require consideration of thermoregulation as discussed in the paper of Gerken (2010).

The paper by Allain and Renieri (2010) focuses on the genetics of fibre production by small ruminants, South American camelids and the Angora rabbit. Consideration is given to differences in fibre properties (physical structure, pigmentation and medullation) and behaviour between primary and secondary HFs in single- and double-coated species. Such differences (single vs double coat) typically include greater secondary to primary ratio, long growth phase (anagen) and relative insensitity to photoperiod/season in addition to uniformity in dimension of primary and secondary fibres. Characteristics of coat composition, hair growth pattern and fibre structure are described as additive in small ruminants, and due to a number of genes, whereas autosomal recessive genes have major influence in the rabbit. Important production traits including fibre yield and quality in certain species are recognised to have moderate to strong heritability although potentially antagonistic if increased yield is achieved by reduced fineness of fibre. The authors describe results from breeding studies and current information 
on the regulation of fleece characteristics in Huacaya and Suri genotypes of Alpaca (see also Antonini, 2010) which are not yet fully explained. Developments in molecular genetics have contributed to the recognition of QTLs and important genes affecting fibre production. In addition, advances in identification of polymorphisms are considered to have potential to advance understanding of the genetic basis of, and selection for, economically valuable production traits.

The application of in vitro methodology, developed from studies on human HFs, to investigation of the regulation of fibre growth in small ruminants is the subject of the paper by Galbraith (2010a). This approach enables measurement of intrinsic growth and physiological/metabolic behaviour of individual, or groups of, isolated anagen HFs in culture media. It also permits measurement of responses to nutrients and/or chemical signalling molecules.

Data are presented which show differences in the structural development, and protein synthesis between mohair and cashmere HFs and which relate to fibre production in vivo. Responses of mohair and cashmere HFs to melatonin and prolactin are described which suggest direct effects of these mediators of photoperiod at the level of individual HF. However, the basis of differences in magnitude of response to changes in photoperiod in vivo between the genotypes remains unclear.

Exposure of mohair HFs to Epidermal growth factor was also shown to produce dose-dependent effects on hair shaft elongation with apparent stimulation of proliferation of outer root sheath and formation of club hair typical of human HFs and follicular anagen/catagen transition in sheep. The essential nature of the B-vitamin biotin, and dose levels required to support ATP production and protein synthesis and viability, in isolated sheep HFs were also demonstrated. Similarly, studies on the sulphur-containing amino acids L-cysteine and L-methionine showed the essential requirement for methionine in maintaining viability and growth of mohair HFs. These studies provide information on likely concentrations of nutrients required in the local environment in skin of individual HFs and which may be utilised in design of practical nutrition for animals in vivo.

The above papers have described a range of important characteristics of fibre and the HFs in which they are produced. The paper by Galbraith (2010b) examines current knowledge on the fundamental biology of the HF and derived from a range of animal species including genetically mutant mice.

The HF is considered as a specialised 'miniorgan' with cellular, extracellular and subcellular components and commonality with other tissues of the integument. The review identifies local interactions and chemical signalling between epidermis (keratinocyte cell lineages; melanocytes) and dermis (fibroblasts; extracellular matrix), which are important in embryonic and subsequent development of different follicle types and which along with systemic sources, regulate $\mathrm{HF}$ cycling. The latter process involves regression of, and apoptosis of cells in, the lower segment of the HF in catagen/telogen and its regeneration from stem cells in new anagen. Important signalling molecules and their inhibitors and antagonists, which are affect morphogenesis (anatomical development) and mitogenesis (cell proliferation) include systemic hormones, locally produced and acting growth factors (paracrine-, autocrine- and juxtacrine-acting molecules) and pathways of transduction of signal into cells. These pathways typically involve different types of receptors, second messengers, phosphorylation and dephosphorylation processes and transcription factors, which affect gene expression. Reference is also made to microRNA species, which influence translation into peptide/protein products. Coverage is given to identification of phenotypic characteristics identified in other workshop papers, such as presence, numbers and type of follicles in skin and suggested role of signalling systems in determining deposition of cytoskeletal keratins and associated proteins, and fibre properties such as length, diameter, medullation, crimp and lustre. The presence, regulation and effect of polymorphic gene variants on HF pigmentation, is also discussed. Attention is also given to use of regulatory and other gene products as potential molecular markers for selection of superior animals in breeding programmes. The review concludes with a review of nutrients necessary to support production of fibre in target species.

\section{Opportunities for the future}

Despite such positive indicators of economic value for producers and processors internationally, natural animal fibres, except in niche higher value markets, have tended to lose competitiveness against synthetic fibre products derived from petroleum oil ('petrocarbons') and indeed natural plant sources in the second half of the 20th century (e.g. Rogers, 2006).

However, the increases in world energy demands, diminishing supply of petrocarbons, and increases in their cost may produce conditions for return to a greater utilisation of natural animal fibres. Such a scenario is particularly important for regions of extensive production and more marginal land where cellulose-based crops are best utilised by herbivorous animals, which do not then directly compete with humans for food. Contemporary issues concerning greenhouse gas production by these animals and impact on the physical environment require to be addressed. This may be best achieved by optimising animal husbandry and improving selection and breeding only of those animals, which produce fibre of required yield and quality to meet the demands of individual markets. The application of scientific knowledge such as provided in the Workshop papers will contribute to underpinning such developments in production. Beneficial results of this approach for Australian Merino sheep, can be seen in the data provided by Lyons (2009), which show improvements in the proportion of the total clip with fibre diameter $<19 \mu \mathrm{m}$ from 0.085 in 1993/1994 to an estimated 0.36 in 2006/2007.

Other opportunities derive from improvement in products such as meat from cull animals and contribution to enhancing the wealth of human populations needed for protection of ecology in rural areas. 
Galbraith

\section{Conclusion}

The Workshop brought together important scientific and practical information on animal fibre production in a global context. The range of subjects covered includes whole animal biology, hair fibre and follicle properties, molecular regulation, genetics and breeding. In providing the written proceedings, the organisers are pleased to contribute to promoting the generation and dissemination of knowledge in animal science and production, and so support the mission and vision of EAAP.

\section{Acknowledgements}

This foreword relates to the papers identified in the text above and based on invited presentation at the 59th Annual Meeting of the European Association for Animal Production held in Vilnius, Lithuania during August 2008.

The organisers are grateful for sponsorship from the University of Camerino and support from EAAP staff in the running of the Workshop. The authors also thank Dr Nic Friggens, Dr Phillipe Guesnet and colleagues from Animal and also external reviewers of our papers.

\section{References}

Allain D and Renieri C 2010. Genetics of fibre production and fleece characteristics in small ruminants, Angora rabbit and South American camelids. Animal 4, 1472-1481.
Antonini M 2010. Hair follicle characteristics and fibre production in South American Camelids. Animal 4, 1460-1471.

Biella the Wool Company 2009. Retrieved March 15, 2010, from http:// www.biellathewoolcompany.com/

British Wool Marketing Board 2009. Retrieved March 15, 2010, from http:// www.britishwool.org.uk/

Cardellino R and Mueller J 2009. Wool and other natural fibres in South America. In Proceedings of the Symposium on Natural Fibres. Common Fund for Commodities, Technical Paper no. 56. FA0, Rome, Italy, pp. 43-52.

Common Fund for Commodities 2009a. International Year of Natural Fibres. Retrieved March 15, 2010, from http://www.naturalfibres2009.org

Common Fund for Commodities 2009b. Proceedings of the Symposium on Natural Fibres. Common Fund for Commodities, Technical Paper no. 56. FAO, Rome, Italy.

Galbraith H 2010a. In vitro methodology, hormonal and nutritional effects and fibre production in isolated ovine and caprine anagen hair follicles. Animal 4, 1482-1489.

Galbraith H 2010b. Fundamental hair follicle biology and fine fibre production in animals. Animal 4, 1490-1509.

Gerken M 2010. Relationships between integumental characteristics and thermoregulation in South American camelids. Animal 4, 1451-1459.

Jianchun Z 2009. Natural fibres in China. In Proceedings of the Symposium on Natural Fibres. Common Fund for Commodities, Technical Paper no. 56. FA0, Rome, Italy, pp. 53-61.

Lyons B 2009. Australian Merino wool. In Proceedings of the Symposium on Natural Fibres. Common Fund for Commodities, Technical Paper no. 56. FAO, Rome, Italy, pp. 83-109.

Rogers GE 2006. Biology of the wool follicle: an excursion into a unique tissue interaction system waiting to be rediscovered. Experimental Dermatology 12 , 931-949.

van Dam J 2009. Natural fibres and the environment-environmental benefits of natural fibre production and use. In Proceedings of the Symposium on Natural Fibres. Common Fund for Commodities, Technical Paper no. 56. FA0, Rome, Italy, pp. 3-18. 